\title{
Ongoing hepatitis A outbreak in Europe 2013 to 2014: imported berry mix cake suspected to be the source of infection in Norway
}

B Guzman-Herrador (BernardoRafael.Guzman.Herrador@fhi.no) ${ }^{1}$, L Jensvoll ${ }^{2}$, M Einöder-Moreno $^{1,3}$, H Lange ${ }^{1,3}$, S Myking $^{1,4}$, K

Nygård $^{1}, K_{\text {K Stene-Johansen }}^{4}$, L Vold ${ }^{1}$

1. Department of Infectious Disease Epidemiology, Norwegian Institute of Public Health, Oslo, Norway

2. Norwegian Food Safety Authority, Head Office, As, Norway

3. European Program for Intervention Epidemiology Training (EPIET), European Centre for Disease Prevention and Control (ECDC), Stockholm, Sweden

4. Department of Virology, Norwegian Institute of Public Health, Oslo, Norway

Citation style for this article:

Guzman-Herrador B, Jensvoll L, Einöder-Moreno M, Lange H, Myking S, Nygård K, Stene-Johansen K, Vold L. Ongoing hepatitis A outbreak in Europe 2013 to 2014: imported berry mix cake suspected to be the source of infection in Norway . Euro Surveill. 2014;19(15): pii=20775. Available online: http://www.eurosurveillance. org/ViewArticle. aspx?Articleld $=20775$

On 7 March 2014, an increase in hepatitis A virus (HAV) infections was identified in Norway. As of 12 April, 19 cases of HAV infection with a virus strain identical to an ongoing European outbreak have been identified. Six probable cases are currently under investigation. On 11 April, a frozen berry mix cake imported from another European country was found as the likely source of the outbreak; the importer has withdrawn the product in Norway.

On 7 March 2014, the Department of Infectious Disease Epidemiology at the Norwegian Institute of Public Health (NIPH) identified an increase in domestic cases of hepatitis A without travel history within the previous six weeks that were notified to the Norwegian Surveillance System for Communicable Diseases (MSIS). Over the past 10 years we have seen one to two domestic cases of hepatitis A notified monthly in Norway [1], with the exception of 2013 when a Nordic outbreak led to increase in notified cases. Between February and March 2014, more than 20 cases of hepatitis A were notified, most of them with no travel history. The patients identified until the beginning of March 2014 were mostly males living in Oslo. An alert was sent on 9 March to the municipal health authorities and to the Norwegian Food Safety Authority (NFSA). On 10 March, in order to inform other European countries about the increase, an urgent enquiry was posted on the European Epidemic Intelligence Information System platform (EPIS) run by the European Centre for Disease Prevention and Control (ECDC).

\section{Initial epidemiological investigation}

Hepatitis $A$ is mainly transmitted by the faecal-oral route from person to person or contaminated food or water. It has an incubation period of approximately 30 days [2]. NIPH initiated exploratory interviews by telephone to obtain information on clinical symptoms and symptom onset, the mode of transmission and possible common exposures among the patients. The structured questionnaire included questions on consumption of food and drinks as well as other information (i.e. household composition, drug use, occupation) in the period from two to six weeks before symptom onset. The results of these interviews suggested a food-borne route of transmission.

In Norway, hepatitis A virus (HAV) is genotyped only in outbreak situations. As soon as the increase in cases was identified, the reference laboratory at the NIPH started to collect all anti-HAV IgM-positive blood samples diagnosed in the local and regional laboratories in 2014.

On 21 March, the first available typing results showed that 16 domestic cases out of 21 had an identical outbreak strain (NOR-2014-V1) of genotype IA based on a $466 \mathrm{bp}$ sequence in the VP $3-\mathrm{VP}_{1}$ region of the HAV genome. To confirm the association with the European Hepatitis A outbreak ongoing since January 2013 that was associated with consumption of frozen berries $[3,4]$, the reference laboratory repeated the sequencing using the region used in the case definition for that outbreak (VP1-2a region, 46obp) [5]. Results from 1 April confirmed that the Norwegian isolates were identical to those in the European outbreak (KF182323) and a message was posted in the European Early Warning and Response System platform (EWRS) on the same day.

\section{Outbreak description}

As HAV is generally only typed during outbreak investigations in Norway, the onset of the outbreak is difficult to determine because HAV samples are only stored for a limited time. As of 12 April, all samples collected 
Cases of hepatitis A infection by week of symptom onset, Norway, November 2013-April 2014 (n=25)

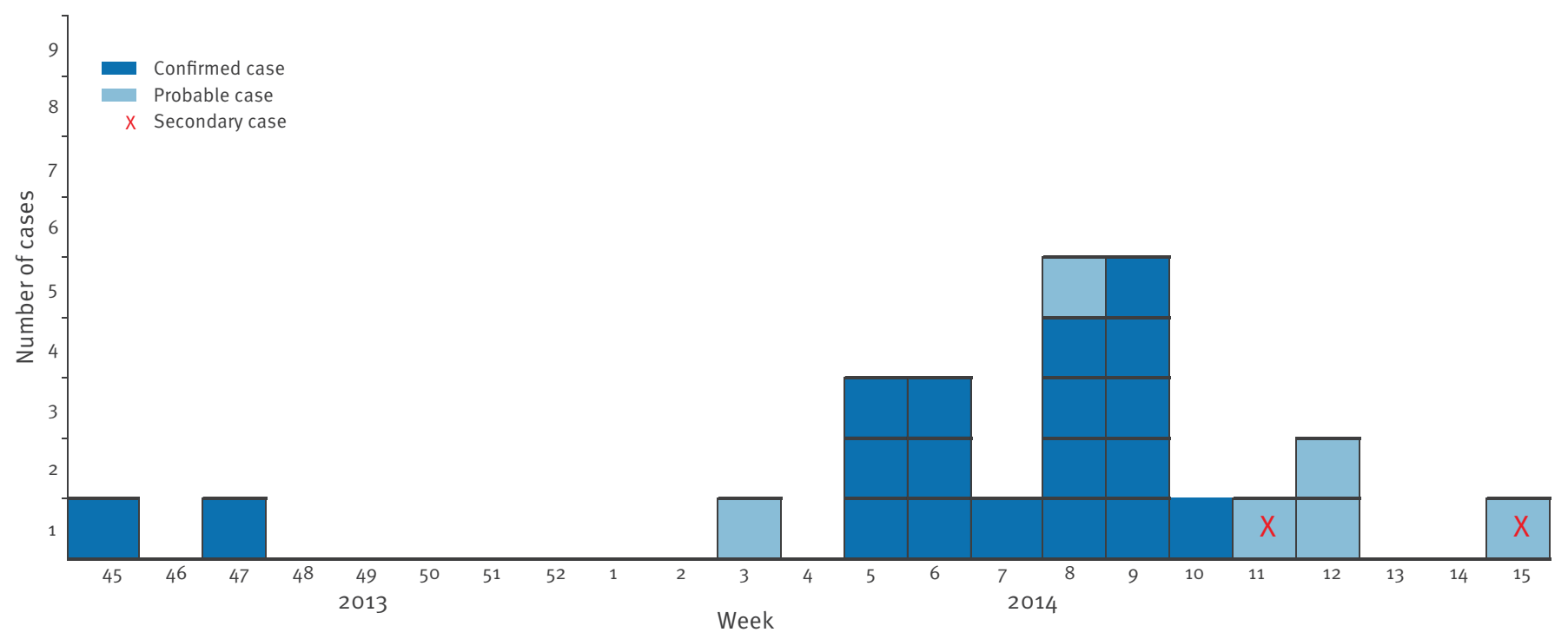

since November 2013 for which serum was still available at local and regional laboratories have been typed and the following outbreak case definition has been developed:

- Probable case: a person living in Norway with clinical illness compatible with HAV infection and serum-positive for HAV IgM antibodies, with onset of symptoms since November 2013 and no travel history to endemic areas two to six weeks before onset of symptoms.

- Confirmed case: a probable case from whom the HAV outbreak strain is identified.

As of 12 April, 25 cases (19 confirmed and six probable) have been identified in Norway. Fifteen cases were men and all were adults (age range: $24-71$ years; median: 43 years). The patients lived in 15 different municipalities, mainly in the south-east region of the country. Onset of symptoms ranged from 7 November 2013 to 9 April 2014. Most of the cases $(n=21)$ had disease onset between Week five and Week 12 (28 January to 21 March). Two of the cases were close contacts of two previously diagnosed cases and were considered secondary cases (Figure). In addition, we were informed, through selective exchange on the EWRS, about a foreign tourist diagnosed with hepatitis $A$ in March, after travelling on a cruise ship along the Norwegian coast in February.

\section{Outbreak investigation}

All primary cases were interviewed. We used trawling questionnaires for the first 13 cases. Different types of berries, salads, vegetables and fruits were the most commonly mentioned food items by the cases. A matched (1:3) case-control study is currently underway to test the hypotheses generated from the trawling questionnaires. A preliminary analysis has been performed including six of the 13 patients already interviewed as well as 10 additional primary cases that had not been interviewed with the trawling questionnaires. No exposure was significantly associated with the disease.

Since the incubation period of hepatitis $A$ is relatively long and recall bias regarding food consumption in the interview results is likely, primary cases were also asked to provide their bank records on food purchases six weeks before disease onset. This was done to support the traceback of food items under suspicion, it allowed shops to provide information on brands and batches of the foods that were being sold at a given point. We were focussing specifically on berries and products containing berries because of the $100 \%$ match with the European outbreak strain identified in the laboratory investigation.

So far, five cases reported to have bought bags of frozen berries during the incubation period. Three of them had berries left in the freezer at the time of the investigation and allowed the NFSA to take samples to test for HAV. Results from samples from two of the patients were negative. Results from samples from the third patient are still pending.

When interviewed, several cases reported that they may have eaten different kinds of cake containing berries during the incubation period. Two cases stated that they had eaten a specific type of berry mix buttermilk cake from the same shopping centre in Oslo. On 9 April, when performing the traceback investigation, the NFSA discovered that the same type of berry cake had been consumed by a third case at a hotel in northern Norway. Company $\mathrm{X}$ had supplied the cake to both locations. On 10 April, NIPH sent an email with 
the photograph of the berry mix buttermilk cake to the remaining cases, asking specifically if they had eaten that cake, and if yes, where they had eaten it. As of 14 April, we have information from 16 cases, of whom 11 confirmed eating the cake. Four could not remember, but said they may have eaten that cake and only one responded that they had not eaten the cake. The traceback investigation indicated that the berry mix buttermilk cake was imported frozen from Germany and distributed to several locations in Norway. Samples have been taken and results are pending.

\section{Public health measures}

On 1 April, as soon as the $100 \%$ match with the HAV strain in the ongoing European outbreak was confirmed, the NFSA and the NIPH informed the public that frozen imported berries should be boiled for one minute before consumption. The ECDC published a rapid outbreak assessment on 11 April, with updated information on the European outbreak, including the cases from Norway [5].

On 10 April, the NFSA alerted the importer of the berry mix buttermilk cake of the suspicion concerning the product. The importer immediately blocked the product in storage and notified their customers to do the same. On 11 April, once the investigation revealed that several more cases had eaten the berry mix buttermilk cake, the NIPH and the NFSA informed the importer and the public that the cake was the likely source of the outbreak. The Norwegian importer immediately withdrew the product from the market in Norway. The cake had been distributed to different restaurants, canteens and cafés in Norway and had been sold in a small number of shops. It had also been distributed to cruise ships sailing along the Norwegian coast. The same day, the NFSA posted a Rapid Alert System for Food and Feed (RASFF) notification about this product and the NIPH updated the EWRS message.

Traceback investigations are still ongoing to determine whether contaminated berries could have been distributed to Norway through other channels. An international traceback investigation is ongoing to find the origin of the berries used in the cake.

\section{Conclusion}

Hepatitis $A$ is a re-emerging foodborne health threat in Europe, illustrated by several multinational outbreaks over the last couple of years [4,6-8]. At least three of these outbreaks have been linked to berries $[4,7,8]$. Consumption of berries has increased from 1.25 to 3.81 kg per capita per year in Norway from 2003 until 2012 [9]. Berries are increasingly imported into Europe, and Norway has seen an increase in import of this product over the last five years. A substantial amount of imported berries are from countries with high endemic levels of hepatitis A [10]. In outbreaks, traceback of these products, especially frozen berries, has proven to be challenging and is illustrated in the current European outbreak in which the origin of the berries has not yet been found. This highlights the need to improve traceback systems for berries imported into Europe. Currently, several countries, including Norway, are participating in a working group, HAVTrace, which is being arranged by the European Commission in collaboration with the European Food Safety Authority (EFSA) and ECDC. The goal is to collect existing evidence and coordinate the traceback activity between the affected countries.

\section{Acknowledgments}

The authors would like to thank all cases involved in this outbreak for being so collaborative during all the steps of the investigation. From the Norwegian Institute of Public health we would like to thank Hans Blystad, Hilde Kløvstad, Øivind Nilsen, Åse Marie Wikman Strand, Kirsten Konsmo, Astrid Louise Løvlie, Terese Bekkevold, Olav Brunborg, and Liv Tone Gaarder for their contributions in the outbreak investigation, Hilde Elshaug for genotyping strains, and Katrine Borgen and Emily MacDonald for giving feedback on the manuscript. We would like to thank also Pawel Stefanoff from the European Programme for Intervention Epidemiology Training (EPIET) for his feedback on the manuscript. We would like to thank Tore Steen and all other municipal health officers involved in the outbreak investigation. From the Norwegian food Safety Authority we would like to thank Torunn Stalheim, Øygunn $\emptyset$ sthagen, Torild Agnalt $\emptyset$ stmo and all other participants from the central and local levels of the food authorities involved in the investigation.

\section{Conflict of interest}

None declared.

\section{Authors' contributions}

LV, KN, BGH, MEM and HL conducted the epidemiological investigation. $L J$ led the traceback investigation. $K S$ J and SM conducted the laboratory investigation. BGH drafted the manuscript. All authors have reviewed and agreed on the content of the manuscript.

References

1. Nasjonalt folkehelseinstitutt. Smittevernboka. [Manual for communicable diseases control]. Oslo: Nasjonal folkehelseinstitutt; 2009. Norwegian.

2. Heymann DL, editor. Control of communicable diseases manual. 19th ed. Washington, DC: American Public Health Association; 2008.

3. European Food Safety Authority, European Centre for Disease Preventionand Control (ECDC). Outbreak of hepatitis A virus infection in residents and travellers to Italy. Rapid outbreak assessment. Stockholm: ECDC; 2013. Available from: http:// ecdc.europa.eu/en/publications/Publications/hepatitis-Aoutbreak-of-hepatitis-A-virus-infection-in-residents-andtravellers-to-Italy.pdf

4. Rizzo C, Alfonsi V, Bruni R, Busani L, Ciccaglione AR, De Medici $\mathrm{D}$, et al. Ongoing outbreak of hepatitis A in Italy: preliminary report as of 31 May 2013. Euro Surveill. 2013;18(27):pii=20518.

5. European Food Safety Authority, European Centre for Disease Prevention and Control (ECDC). Outbreak of hepatitis A in EU/ EEA countries - Second update, 11 April 2014. Stockholm: ECDC; 2014. Available from: http://www.ecdc.europa.eu/ en/publications/Publications/ROA-Hepatitis\%20A\%20virus Italy $\% 20$ Ireland $\% 20$ Netherlands $\% 20$ Norway $\% 20$ France $\% 20$ Germany\%20Sweden\%20United\%20Kingdom\%20-\%2ofinal. pdf

6. Carvalho C TH, Balogun K, Tedder R, Pebody R, Ramsay M, Ngui SL. A possible outbreak of hepatitis A associated with 
semi-dried tomatoes, England, July-November 2011. Euro Surveill. 2012;17(6): pii=20083.

7. MacDonald E SA, Stene-Johansen K, Gillesberg Lassen S,

Midgley SE, Lawrence J, Crofts J, et al. Increase in hepatitis A

in tourists from Denmark, England, Germany, the Netherlands, Norway and Sweden returning from Egypt, November 2012 to March 2013. Euro Surveill. 2013;18(17):pii=20468.

8. Nordic outbreak investigation team. Joint analysis by the Nordic countries of a hepatitis A outbreak, October 2012 to June 2013: frozen strawberries suspected. Euro Surveill. 2013;18(27):pii=20520.

9. Totaloversikten. Frisk frukt, bær, grønnsaker og poteter 2003-2012. [Full overview. Fresh fruit, berries, vegetables and potatoes 2003-2012]. Oslo: Information Office for fruit and vegetables; 2013. Norwegian. Available from: http://www. frukt.no/sitefiles/1/vedlegg/ofg_total2012.pdf

10. Utenrikshandel med varer. [Foreign trade with goods]. Oslo: Statistics Norway. [Accessed: April 2014]. Norwegian. Available from: www.ssb.no 